\title{
Histological intersex (ovotestis) in the European lobster Homarus gammarus and a commentary on its potential mechanistic basis
}

\author{
G. D. Stentiford ${ }^{*}$ \\ European Union Reference Laboratory for Crustacean Diseases, Centre for Environment, \\ Fisheries and Aquaculture Science (Cefas), Weymouth Laboratory, Weymouth, Dorset DT4 8UB, UK
}

\begin{abstract}
This paper provides the first report of the intersex (ovotestis) condition in the European lobster Homarus gammarus. A single specimen (10\% of males sampled) presenting the condition was discovered as part of routine sampling, from the Weymouth Bay region of the English Channel, UK. The lobster presented externally as a male, but upon histological examination was seen to contain an ovotestis, containing elements of both male and female gonadal tissue. Previtellogenic oocytes were present in several otherwise normal seminiferous tubules throughout the testis. The seminiferous tubules were also engaged in the production of apparently normal sperm lineages, and mature spermatozoa were present within the tubule lumens. In some cases, oocytes were in direct contact with mature spermatozoa within the same seminiferous tubules. The significance of this finding is placed into context with a previous observation of elevated intersexuality in the congeneric species $H$. americanus collected from specific sites in Canadian waters. The potential mechanism for development of intersex in lobsters, which is probably related to a disrupted signalling to the germinal component of the testis from the decapod androgenic gland, may be an effect of exposure to endocrine disrupting chemicals in the marine environment.
\end{abstract}

KEY WORDS: Crustacean $\cdot$ Decapoda $\cdot$ Androgenic gland $\cdot$ Endocrine disruption $\cdot$ Commercial fishery

\section{INTRODUCTION}

Intersexuality is a phenomenon whereby an individual of a species with separate sexes has morphological characteristics that are intermediate between true male and true female forms of that species. The changes may be restricted to alterations in external morphology or to internal changes in the presence, structure and function of the sex organs (Sagi et al. 1996, 2002). In aquatic systems, intersexuality has been widely reported in several species of freshwater (e.g. Jobling et al. 1998), estuarine (e.g. Allen et al. 1999, Stentiford et al. 2003) and marine teleost fish (e.g. Stentiford \& Feist 2005). In most of these cases, the condition manifests as the presence of so-called ovotestes, a combination of male testicular tubules containing different developmental stages of the spermatogonial lineage and oocytes at varying degrees of vitellogenic development. In some fish species, the degree of replacement of normal testicular tissue with oocytes has been graded into severity indices based upon histological criteria (see Bateman et al. 2004). The context for the majority of studies into intersexuality and related sexual perturbations in wild fish has been the significant interest in the effect of the contamination of aquatic systems with 
so-called 'endocrine disrupting chemicals' (EDCs) of anthropogenic origin. EDCs have been widely reported to impair fertility, development, growth and metabolism in a range of animal groups (Colborn et al. 1996). These effects include altered maturation, elevated concentrations of vitellogenin (egg yolk protein) in blood of male fish and the presence of ovotestes in phenotypic males (Gimeno et al. 1996).

Intersexuality and other sexual anomalies have also been observed in aquatic crustaceans. Amongst the nondecapod crustaceans, intersexuality has been reported as a relatively common phenomenon in amphipods from a wide range of aquatic habitats, although the cause is somewhat enigmatic, ranging from feminisation by parasite infection (Tang et al. 2005) through environmental sex determination, to industrial pollution (see Ford \& Fernandes 2005). Similar reports have also been published concerning intersexuality in copepods (Markevitch 1982, Ianora et al. 1987, Moore \& Stevenson 1991, 1994) and isopods (Munro 1953, Smith 1977, Korczynski 1985). In the majority of these cases, intersexuality has been reported as a manifestation of various anomalies in the external morphology of the abdomen and its appendages (see Moore \& Stevenson, 1994). In the decapod crustaceans, one manifestation of intersexuality involves the presence of externally visible male and female genital openings. In the Norway lobster Nephrops norvegicus, the blue crab Callinectes sapidus, the European lobster Homarus gammarus and in several species of hermit crabs, this has been shown in some cases to correspond to complete internal bilateral separation of the reproductive system into male and female components, forming a socalled gynandromorph (Gordon 1957, Chace \& Moore 1959, Farmer 1972, Johnson \& Otto 1981, Sant'Anna et al. 2010). Similar externally visible male and female genital openings have been reported for the freshwater crayfish Cherax quadricarinatus. In these cases, although all intersex individuals contained a male testis and an associated sperm duct and androgenic gland, not all crayfish contained a female reproductive system (Sagi et al. 1996). It was concluded from these studies that intersex C. quadricarinatus are functional males (Medley et al. 1994, Sagi et al. 1996). More recent work has demonstrated that the androgenic gland regulates the development of male sexual characteristics in crustaceans and that its absence (or removal) results in feminisation (Sagi et al. 1997, 2002). Finally, in addition to the discovery of occasional gynandromorphic forms, one study on American lobster $H$. americanus reported histological intersex in individuals sampled from the Nova
Scotian fishery for this species. In these cases, the testes contained varying numbers of previtellogenic oocytes within testicular lobules filled otherwise with typical spermatogenic lineages (Sangalang \& Jones 1997). Since the highest prevalence $(28 \%)$ corresponded to a defined location and was particularly elevated compared with 5 other sampling sites $(9 \%)$, the authors suggested the possibility of some implicating environmental factors in driving this high prevalence. The latter case of intersex is particularly noteworthy since it directly mimics that observed in teleost fish and, further, is quite distinct from other forms of intersex observed in the lower and higher crustaceans. Depledge \& Billinghurst (1999) propose that the development of true ovotestes in lobsters is an example of a histopathological biomarker that may be used in surveys aimed at detecting the outcome of anthrogenic contaminant insult in aquatic crustaceans.

Although the Sangalang \& Jones (1997) study reported the presence of histological intersex in lobsters, the full report with graphical representation of the pathology is not available (R. J. Cawthorn pers. comm.). In the present study, we report on the first observed case of histological intersex in the European lobster Homarus gammarus sampled from the UK fishery. We discuss the case in relation to the apparent propensity for the intersex condition in homarid lobsters.

\section{MATERIALS AND METHODS}

Twenty European lobsters Homarus gammarus were collected from commercial fishers as part of an ongoing survey of crustacean health and disease in UK waters. Specifically, lobsters were sampled from a population in the Weymouth Bay region $\left(50^{\circ} 34^{\prime} \mathrm{N}\right.$, $2^{\circ} 22^{\prime} \mathrm{W}$ ). The carapace length, sex and any external abnormalities were recorded prior to dissection. All sampled lobsters appeared externally normal and 10 $(50 \%)$ presented externally as males. Lobsters were anaesthetised by chilling on ice for $30 \mathrm{~min}$ prior to dissection. For histopathology, the hepatopancreas, gills, heart, midgut, gonad and skeletal muscles from the abdomen and chelipeds were dissected from each specimen. Excised samples were placed immediately into Davidson's seawater fixative. Fixation was allowed to proceed for $24 \mathrm{~h}$ before samples were transferred to $70 \%$ industrial methylated spirit for storage prior to processing. Fixed samples were dehydrated and embedded in wax in a vacuum infiltration processor using standard protocols. Sections 
were cut at a thickness of 3 to $5 \mu \mathrm{m}$ on a rotary microtome and were mounted onto glass slides before staining with haematoxylin and eosin (H\&E). Stained sections were analysed by light microscopy (Nikon Eclipse E800) and digital images were taken using the Lucia ${ }^{\text {TM }}$ Screen Measurement System (Nikon).

\section{RESULTS}

External visual examination of European lobsters sampled from the Weymouth Bay site revealed 10 normal male and 10 normal female animals. During histological examination of the tissues and organs from these lobsters, one of the males, with a carapace length of $112 \mathrm{~mm}$, displayed abnormal gonadal development consistent with the 'ovotestis' condition described in numerous species of marine teloest fish (e.g. Bateman et al. 2004).

The majority of the gonadal tissue mass within the intersex lobster consisted of apparently normal seminiferous tubules containing a progressive lineage of male reproductive cell types. Spermatogonia and accessory cells lined the basement membrane of individual seminiferous tubules, and apparent spermatocytes and mature spermatozoa were found in the luminal region of each tubule (Fig. 1A). Closely opposed seminiferous tubules at similar stages of development were present throughout the testis. Seminiferous tubules delivered mature spermatozoa
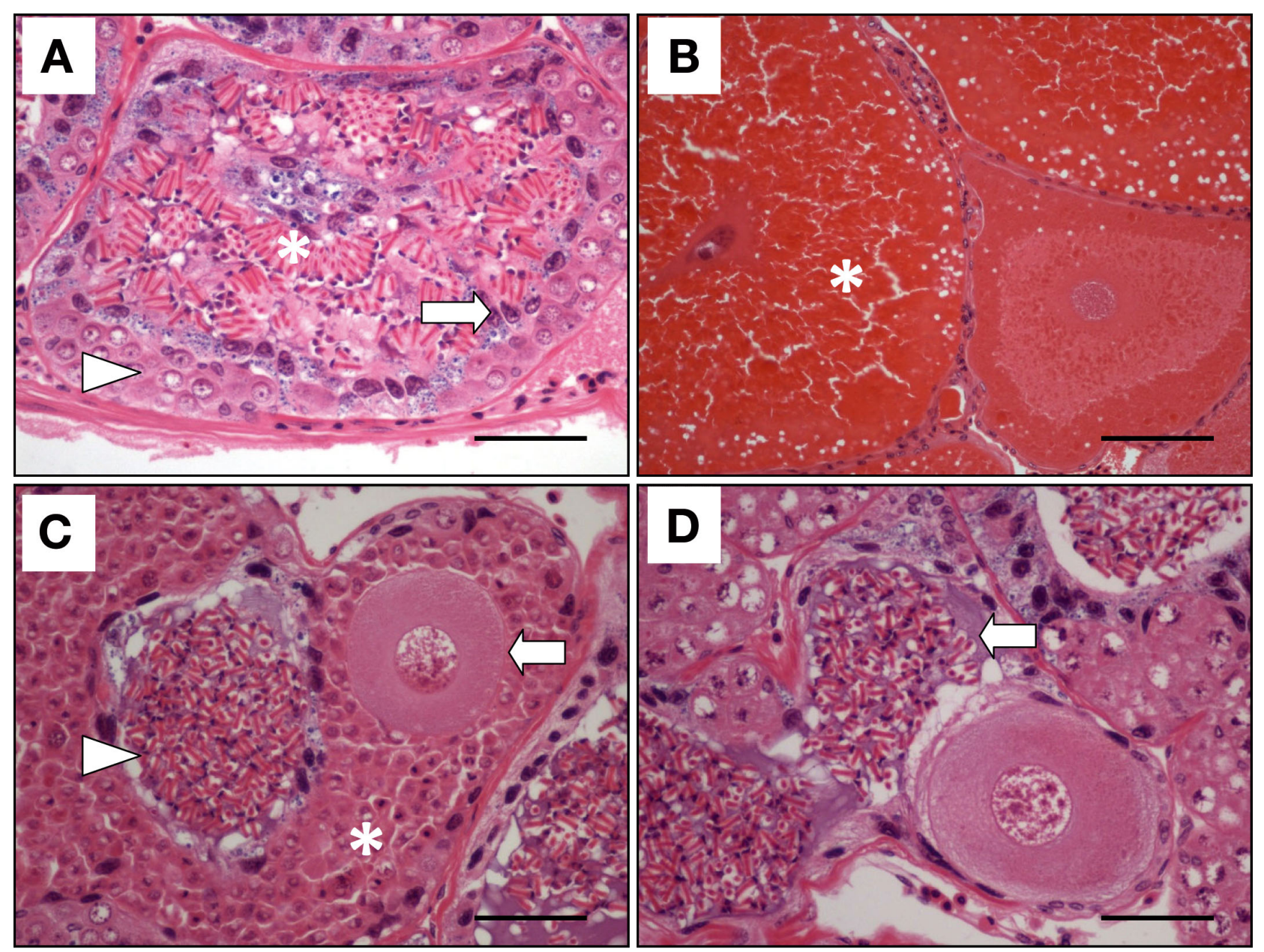

Fig. 1. Homarus gammarus. Intersex (ovotestes) in the European lobster. H\&E staining. (A) Normal seminiferous tubule from a male lobster containing spermatogonia and accessory cells (arrowhead), spermatocytes (arrow) and mature spermatozoa in the central lumen (asterisk). (B) Normal oocytes from a female lobster. Vitellogenic oocytes (asterisk) occur alongside earlier previtellogenic development stages. (C) Isolated previtellogenic oocyte (arrow) in direct contact with germinal cells of uncertain origin (asterisk) and adjacent to a lumen containing mature spermatozoa (arrowhead). (D) Isolated previtellogenic oocyte apparently within the lumen of the seminiferous tubule, in direct contact with mature spermatozoa (arrow). Both (C) and (D) show histological manifestation of ovostestes. Scale bars $=100 \mu \mathrm{m}$ 
to the vas deferens (not shown). Normal testicular structure contrasted that observed in females from the same batch, in which previtellogenic and vitellogenic oocytes were in all specimens observed (Fig. 1B). Ovotestis was observed in numerous individual seminiferous tubules throughout the gonad of the affected lobster. In all cases, developing oocytes were either closely associated with the germinal cells at the periphery of the seminiferous tubules (Fig. 1C) or, in some cases, occurred in direct contact with the mature spermatozoa within the lumen of the seminiferous tubule (Fig. 1D). In all cases, oocytes were immature, and there were no signs of vitellogenin accumulation within the oocyte cystoplasm. Despite the apparent confluent presence of immature oocytes with mature spermatozoa, no liberated oocytes were observed within the lumen of the vas deferens (image not shown). In contrast to the normal seminiferous tubules in the remainder of the testis (Fig. 1A), tubules containing ovotestis appeared to contain germinal cells of uncertain origin, in which the nuclei were considerably smaller than that observed in normal spermatogonia (Fig. 1C).

\section{DISCUSSION}

This is the first report on the occurrence of histologically confirmed ovotestes in the European lobster Homarus americanus and one of very few studies that have demonstrated the potential for this condition to develop in the Crustacea. Out of the 10 male lobsters sampled, one displayed this condition. Despite previous reports of gynandromorphy in $H$. americanus (Chace \& Moore 1959) and one other species of homarid lobster, Nephrops norvegicus (Farmer 1972), the condition reported here did not present as an internal bilateral separation of the reproductive system into male and female components (as in gynandromorphy), but instead by the presence of apparently previtellogenic oogonia and otherwise normal spermatogonial cell lineages within the same testicular tubules. In this respect, the condition is identical to that observed in numerous species of teleost fish sampled from freshwater, estuarine and marine habitats (for examples see Jobling et al. 1998, Allen et al. 1999, Stentiford et al. 2003, Stentiford \& Feist 2005). The most significant reference to this condition in the crustacean literature is that of Sangalang \& Jones (1997), who reported on an identical condition in the sister species, H. americanus, from marine sites in Nova Scotia, Canada. Although only available as an abstract, this report provided evidence that up to $28 \%$ of male lobsters sampled from the Dartmouth Cove site contained ovotestes whilst the condition was less frequent (9\%) at 5 other field sites visited during the study period. As part of that study, those authors also reported on occasional occurrences of gynandromorphy in $H$. americanus from the region and proposed that some environmental forcing factors may be implicated in the higher prevalence of such sexual perturbations in lobsters from the Dartmouth Cove site (Sangalang \& Jones 1997).

Ginsburger-Vogel \& Charmain-Cotton (1982) and Charniaux-Cotton \& Payen (1985) demonstrated that the androgenic gland, situated within the distal vas deferens of most decapods, is likely to be the exclusive source of the hormone responsible for sex differentiation in crustaceans. The gland has been the subject for considerable study of endocrine regulation of sex differentiation in decapods (Sagi et al. 1997). Early studies on ablation of the gland in amphipods led to decreased spermiogenesis in males (Charniaux-Cotton 1954). Ablation of the gland in males of the prawn Macrobrachium rosenbergii led to initiation of oogenesis and development of oviducts and female gonopores (Nagamine et al. 1980). Furthermore, the effect of androgenic gland ablation was shown to be dependent on the age of the recipient animal; older males underwent reduced testicular development whilst younger males developed ovotestes, albeit apparently separated into different zones of the same lateral gonad (Sagi et al. 1997). In other work, complete surgical removal of the androgenic gland of juvenile $M$. rosenbergii led to the development of functional females capable of mating and producing offspring (Sagi et al. 1997). Reciprocal experiments on young female $M$. rosenbergii receiving androgenic gland implants led to sex reversal to functional males (Malecha et al. 1992). Finally, implantation of ovarian material in androgenic glandablated males led to development of female sexual characters, suggesting that the androgenic gland prevents the appearance of female characteristics in early life stages by inhibiting the differentiation of the juvenile gonad to form an ovary (Nagamine \& Knight 1987, Sagi et al. 1997). This separation of the organ regulating sexual differentiation from the gametogenic organ (i.e. the testis) is unlike the single organ system observed in vertebrates (Ventura et al. 2009).

Male differentiation in crustaceans is probably controlled by a secretion from the androgenic gland along the genital tract to the site of action, the testis. In the absence of a gland (or, presumably, disruption 
in its action), differentiation of an ovary can occur (Charniaux-Cotton 1959, Sagi et al. 1996, 1997). Most early work on the nature of the hormone produced by the androgenic gland was carried out in isopods where the substance was shown to be proteinaceous, and was similar to the proinsulin family of peptides (Katakura et al. 1975, Martin et al. 1990, Okuno et al. 1999). More recent studies using suppressive subtractive hybridisation (SSH) have identified a male specific gene expressed in the androgenic gland of crayfish (Cherax quadricarinatus insulin-like AG factor; Cq-IAG) (Manor et al. 2007). Subsequent studies on Macrobrachium rosengergii revealed a similar insulin-like peptide-coding gene specific to the androgenic gland (Mr-IAG), which after silencing with RNA interference (RNAi) affected the development of male sexual characters, the arrest of spermiogenesis and the pathology of the androgenic gland itself (Ventura et al. 2009). Similar approaches to silencing of the Cq-IAG in crayfish led to male feminisation, reduced sperm production, testicular degeneration, expression of the vitellogenin gene and accumulation of yolk proteins in the developing oocytes of the ovotestis. A similar pathology to that previously reported in $M$. rosenbergii was also reported in the androgenic gland itself (Rosen et al. 2010). These studies demonstrate that silencing of the androgenic glandspecific insulin-like gene can feminise the male phenotype in decapod crustaceans.

The discovery of the ovostestis condition in marine lobsters of the genus Homarus, both from the present study and that of Sangalang \& Jones (1997), provides an intriguing insight into the potential for disruption of the sexual phenotype in wild marine crustaceans. Whilst detailed studies on the mechanistic basis for this disruption in marine lobsters has not occurred to date, data arising from experiments on freshwater decapods appear to implicate a likely disturbance in the normal functioning of the androgenic gland in these animals. In light of an increasing appreciation of the potential for so-called endocrine disruption-related phenomena in aquatic crustaceans (Depledge \& Billinghurst 1999, Yang et al. 2008), it is important to understand the effect of anthropogenic chemical contaminants on gene expression and related phenotype in this invertebrate animal group. Furthermore, it is time to readdress our interpretation of this subject matter as not simply a comparison to the mechanism of endrocrine disruption in aquatic vertebrates, but rather to the disturbance of hormonal signalling mechanisms specific to the invertebrates.
Acknowledgements. G.D.S. acknowledges funding to the European Union Reference Laboratory for Crustacean Diseases by DG SANCO of the European Commission (Cefas contract C5202) and the UK Department for Environment, Food and Rural Affairs (Defra) under Cefas contract FB002.

\section{LITERATURE CITED}

Allen Y, Scott AP, Matthiessen P, Haworth S, Thain JE, Feist SW (1999) Survey of estrogenic activity in United Kingdom estuarine and coastal waters and its effect on gonadal development of the flounder Platichthys flesus. Environ Toxicol Chem 18:1791-1800

> Bateman KS, Stentiford GD, Feist SW (2004) A ranking system for the evaluation of intersex condition in European flounder (Platichthys flesus). Environ Toxicol Chem 23: 2831-2836

Chace AF, Moore GM (1959) A bicolored gynandromorph of the lobster, Homarus americanus. Biol Bull (Woods Hole) 116:226-231

Charniaux-Cotton H (1954) Découverte chez un Crustacé Amphipode (Orchestia gamarella) d'une glande endocrine responsible de la différenciation des caractéres sexuels primaries et secondaires males. C R Acad Sci Paris 239:780-782

Charniaux-Cotton H (1959) Étude comparée du développement post-embryonnaire de l'appareil génital et de la glande androgène chez Orchestia gammarella et Orchestia mediterranea (Crustacos Amphipodes). Autodifférenciation ovarienne. Bull Soc Zool Fr 84:105-115

Charniaux-Cotton H, Payen G (1985) Sexual differentiation. In: Bliss DE, Mantel LH (eds) The biology of Crustacea, Vol 9. Academic Press, Orlando, FL, p 217-299

Colborn T, Dumanoski D, Myers JP (1996) Our stolen future. Dutton, New York, NY

> Depledge MH, Billinghurst Z (1999) Ecological significance of endocrine disruption in marine invertebrates. Mar Pollut Bull 39:32-38

- Farmer AS (1972) A bilateral gynandromorph of Nephrops norvegicus (Decapoda: Nephropidae). Mar Biol 15: 344-349

> Ford AT, Fernandes TF (2005) Notes on the occurrence of intersex in amphipods. Hydrobiologia 548:313-318

> Gimeno S, Gerritson A, Bowmer T, Komen H (1996) Feminization of male carp. Nature 384:221-222

Ginsburger-Vogel T, Charmain-Cotton H (1982) Sex determination. In: Abele LG (ed) The biology of Crustacea, Vol 2. Academic Press, Orlando, FL, p 257-281

Gordon I (1957) A pseudo-hermaphrodite specimen of the lobster, Homarus gammarus (Linneaus). Ann Mag Nat Hist 15:524-528

> Ianora A, Mazzochi MG, Di Carlo BS (1987) Impact of parasitism and intersexuality on Mediterranean populations of Paracalanus parvus (Copepoda: Calanoida). Dis Aquat Org 3:29-36

Jobling S, Nolan M, Tyler CR, Brightly G, Sumpter JP (1998) Widespread sexual disruption in wild fish. Environ Sci Technol 32:2498-2506

Johnson TP, Otto SV (1981) Histology of a bilateral gynandromorphy of the blue crab, Callinectes sapidus Rathbun (Decapoda: Portunidae). Biol Bull (Woods Hole) 161: 236-245

Katakura Y, Fujimaki Y, Unno K (1975) Partial purification and characterisation of androgenic gland hormone from 
the isopod crustacean, Armadillidium vulgare. Annot Zool Jpn 48:203-209

Korczynski RE (1985) Intersexuality in the arctic isopod Mesidotea (= Saduria) sibirica. Arctic 38:68-69

Malecha SR, Nevin PA, Ha P, Barck LE, Lamadrid-Rose Y, Masuno S, Hedgecock D (1992) Sex-ratios and sexdetermination in progeny from crosses of surgically sex-reversed freshwater prawns, Macrobrachium rosenbergii. Aquaculture 105:201-218

> Manor R, Weil S, Oren S, Glazer L and others (2007) Insulin and gender: an insulin-like gene expressed exclusively in the androgenic gland of the male crayfish. Gen Comp Endocrinol 150:326-336

Markevitch GI (1982) Intersexuality in Eudiaptomus gracilis (Crustacea, Copepoda). Zool Zh 61:140-143

Martin G, Juchault P, Sorokine O, van Dorsselaer A (1990) Purification and characterization of androgenic hormone from the terrestrial isopod Armadillidium vulgari Latr. (Crustacea, Oniscidea). Gen Comp Endocrinol 80:349-354

Medley P, Camus A, Tiersch T, Avault JW (1994) Hermaphroditic Australian red claw crayfish (Cherax quadricarinatus). J Shellfish Res 12:93-94

Moore CG, Stevenson JM (1991) The occurrence of intersexuality in harpacticoid copepods in relationship with pollution. Mar Pollut Bull 22:72-74

Moore CG, Stevenson JM (1994) Intersexuality in benthic harpacticoid copepods in the Firth of Forth, Scotland. J Nat Hist 28:1213-1230

Munro WR (1953) Intersexuality in Asellus aquaticus L. parasitised by a larval acanthocephalan. Nature 172:313

Nagamine C, Knight AW (1987) Masculinization of female crayfish, Procambarus clarkii (Girard). Int J Invertebr Reprod Dev 11:77-85

Nagamine C, Knight AW, Maggenti A, Paxman G (1980) Effects of androgenic gland ablation on male primary and secondary sexual characteristics in the Malaysian prawn Macrobrachium rosenbergii (de Man) (Decapoda, Palemonidae), with first evidence of induced feminization in a nonhermaphrodite decapod. Gen Comp Endocrinol 41:423-441

Okuno A, Hasegawa Y, Ohira T, Katakura Y, Nagasawa $\mathrm{H}$ (1999) Characterization and cDNA cloning of androgenic gland hormone of the terrestrial isopod Armadillidium vulgare. Biochem Biophys Res Commun 264: 419-423

Editorial responsibility: Sven Klimpel,

Frankfurt, Germany
Rosen O, Manor R, Weil S, Gafni O and others (2010) A sexual shift induced by silencing of a single insulin-like gene in crayfish: ovarian upregulation and testicular degeneration. PLoS ONE 5:e15281

Sagi A, Khalaila I, Barki A, Hulata G, Karplus I (1996) Intersex red claw crayfish, Cherax quadricarinatus (von Martens): functional males with pre-vitellogenic ovaries. Biol Bull (Woods Hole) 190:16-23

> Sagi A, Snir E, Khalaila I (1997) Sexual differentiation in decapod crustaceans: role of the androgenic gland. Invertebr Reprod Dev 31:55-61

Sagi A, Manor R, Segall C, Davis C, Khalaila I (2002) On intersexuality in the crayfish Cherax quadricarinatus: an inducible sexual plasticity model. Invertebr Reprod Dev 41:27-33

Sangalang G, Jones G (1997) Oocytes in the testis and intersex in lobsters (Homarus americanus) from Nova Scotian sites: natural or site-related phenomenon? Can Tech Rep Fish Aquat Sci 2163:46 (Abstract)

Sant'Anna BS, Turra A, Zara FJ (2010) Simultaneous activity of male and female gonads in intersex hermit crabs. Aquat Biol 10:201-209

Smith DG (1977) An occurrence of a female intersex of Asellus communis Say (Isopoda, Asellidae). Crustaceana 32: 89-90

Stentiford GD, Feist SW (2005) First reported cases of intersex (ovotestis) in the flatfish species dab Limanda limanda: Dogger Bank, North Sea. Mar Ecol Prog Ser 301:307-310

Stentiford GD, Longshaw M, Lyons BP, Jones G, Green M, Feist SW (2003) Histopathological biomarkers in estuarine fish species for the assessment of biological effects of contaminants. Mar Environ Res 55: $137-159$

Tang B, Wang Q, Chen L, Yang S (2005) Features of an intersex Chinese mitten crab, Eriocheir japonica sinensis (Decapoda, Brachyura). Crustaceana 78:371-377

> Ventura T, Manor R, Aflalo ED, Weil S, Raviv S, Glazer L, Sagi A (2009) Temporal silencing of an androgenic gland-specific insulin-like gene affecting phenotypical gender differences and spermatogenesis. Endocrinology 150:1278-1286

> Yang G, Kille P, Ford AT (2008) Infertility in a marine crustacean: Have we been ignoring pollution impacts on male invertebrates? Aquat Toxicol 88:81-87

Submitted: February 13, 2012; Accepted: February 14, 2012 Proofs received from author(s): April 24, 2012 